TAS Journal, vol. 5, n. 2, p. 29-44

ISSN 2595-1521

MARCH 2021

giselecristinabessa@gmail.com

\title{
Estimativa de benefícios na implementação de projeto de automação da etiquetagem de embalagens na indústria têxtil
}

\author{
Petri R*, Maestri G*, Bessa GC*, Steffens F*, Oliveira FR*, Forno AJD*, Rincon \\ LM*, Merlini C§ e Souza, AAU*
}

*Universidade Federal de Santa Catarina, PGETEX, Blumenau, Brasil. §Coordenadoria Especial de Engenharia de Materiais, Universidade Federal de Santa Catarina, Blumenau, Brasil.

Resumo: A indústria têxtil e confecção tem se caracterizado como intensivas em mão de obra, entretanto os processos de automação vêm ganhando espaço nestes ambientes industriais. Um processo como o de etiquetagem no setor de embalagem industrial, quando realizado manualmente, está sujeito a erros e desperdícios indesejáveis, porém, este processo manual ainda é realidade em muitas indústrias têxteis e de confecção no Brasil. Neste trabalho é apresentado um modelo de automação para o processo de etiquetagem no setor de embalagem da indústria têxtil e confecção, sustentado por princípios da teoria de mecanismos, sistemas de automação, gerenciamento de pessoas, tempo de ciclo de operação e análise financeira. Os resultados teóricos previstos, após a implementação do modelo de automação, indicam uma redução no tempo de ciclo do processo de aproximadamente 14,3\%, com investimento que se pagará em cerca de 5,8 anos. A implementação de mecanismos de automação possibilita, neste caso, a otimização e melhoria dos processos na indústria têxtil e confecção em termos de agilidade, precisão e redução de custo.

Palavras-chave. Indústria têxtil, confecção, sistemas de automação industrial, otimização de processos.

Introdução. A produção do vestuário inicia na produção do fio, seguido da tecelagem ou malharia, processos de beneficiamento (tinturaria e acabamentos), estamparia, confecção, entre outros (1, 2). Um grande desafio da indústria têxtil e confecção atualmente é acompanhar as tendências de mercado, tendo que se adaptar às condições flexíveis de produção, permitindo que a empresa siga as grandes flutuações na demanda, bem como atenda aos pedidos de produtos em menor escala e customizados (3).

Os processos automatizados vêm ganhando espaço em várias indústrias, assim como na área têxtil e confecção (4, 5). Automação pode ser definida como qualquer sistema, eletrônicos e computadorizados, que substitua o trabalho humano em favor da segurança das pessoas, da qualidade dos produtos, da rapidez da produção ou da redução de custos, assim aperfeiçoando os complexos objetivos das indústrias e dos serviços, (6). 
Os sistemas automatizados permitem a melhoria da produtividade e qualidade, realização de tarefas complexas e a redução do esforço de trabalho em processos industriais $(7,8)$.

A utilização de robôs, em tarefas antes realizadas manualmente, resulta em maior confiabilidade do processo, por serem menos propensos a cometerem erros durante a realização da atividade, principalmente em tarefas que exigem repetibilidade e precisão. Outro fator a ser considerado é o aumento da produtividade, pois os robôs que atuam em sistemas automatizados não necessitam de férias e podem trabalhar em condições adversas e extenuantes $(9,10)$.

Diversos setores da cadeia têxtil já foram automatizados, como os processos de colheita da pluma do algodão, os equipamentos para a realização de testes de qualidade de fios, e a otimização da sala de abertura, limpeza e mistura de fibras. Na fiação se destacam os robôs que auxiliam na emenda dos fios e adaptações robotizadas diversas em maquinário. No setor de tecelagem os sistemas de inserção do fio de trama apresentam maior velocidade em teares de tecidos planos. Na área da tinturaria a automação possibilitou o controle preciso de parâmetros essenciais de processo, como temperatura, tempo, pressão e $\mathrm{pH}$, redução do consumo de água e o transporte de bobinas realizado por robôs (3). Na confecção as máquinas de costura possuem sistema de troca de bobinas automáticas, realização de costuras pontuais automáticas, entre outros $(11,12)$.

O processo de embalagem e etiquetagem dos produtos são etapas importantes nas indústrias têxteis e de confecção. As peças de roupas necessitam de uma embalagem para garantir que o produto permaneça limpo e em bom estado para o comércio. O processo de etiquetagem se faz necessário para a identificação dos produtos, facilitando o processo de venda e o controle de estoque, uma vez que o vestuário é vendido baseado na sua descrição e preço, identificado normalmente por um código de barras ou QRcode $(13,14)$. Todavia, este processo é, na maioria das vezes, realizado de forma manual, o que acarreta erros e desperdícios do processo supracitado (14).

Vislumbra-se, portanto, um nicho de oportunidade de melhoria deste processo utilizando os conceitos de automação, para o aumento da eficiência da atividade de etiquetagem de produtos, com maior agilidade e qualidade na operação.

A justificativa do presente trabalho se dá pelos vários processos da indústria têxtil que ainda são realizados de forma manual, o que gera elevados índices de desperdícios, ambientais, financeiro e de tempo, lentidão no processo, podendo comprometer a qualidade do produto.

Portanto, é proposto neste trabalho um modelo de automação baseado em um processo de etiquetagem de produtos da área têxtil e confecção, com o intuito de caracterizar e analisar os requisitos gerais e detalhados do sistema de automação e realizar a análise financeira do projeto, a fim de proporcionar a redução dos custos e o aumento da eficiência da indústria no processo de etiquetagem de produto. 
Caracterização básica do projeto. O projeto trata da automação de um processo de etiquetagem de embalagens para travesseiros (que no decorrer desse trabalho será tratado como Produto A). A caracterização básica do projeto referente ao estado atual do processo é ilustrada da Fig.1.

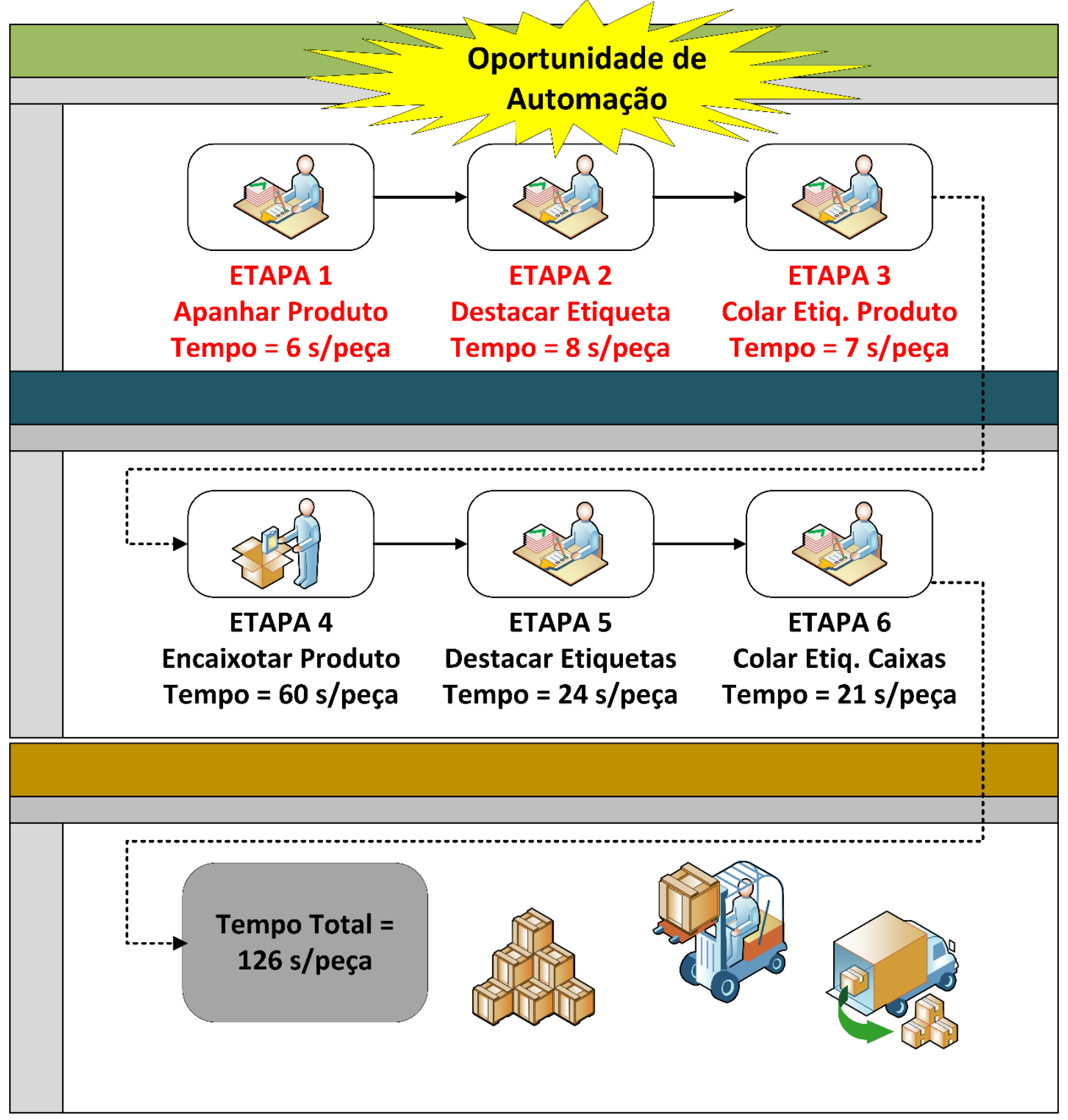

Figura 1. Processo de etiquetagem do produto A (estado atual). 
Com base na Fig.1, é possível analisar o conjunto de operações relacionadas ao processo de etiquetagem do produto A; os tempos de ciclo em segundos por peça; os estoques; as entradas e saídas, bem como oportpeças de automação para as operações: apanhar produto acabado, destacar etiqueta do tipo 01 (etiqueta de composição) e colocar a etiqueta do tipo 01 no produto acabado.

A Tab.1 aborda uma narrativa detalhada das operações existentes no processo do produto A, bem como as operações que se pretende automatizar.

Tabela 1. Narrativa detalhada das operações do processo de etiquetagem do produto A (estado atual).

\begin{tabular}{|c|l|c|l|}
\hline Seq. & \multicolumn{1}{|c|}{ Descrição das operações } & Seq. & \multicolumn{1}{|c|}{ Descrição das operações } \\
\hline $\begin{array}{c}1 \\
(*)\end{array}$ & $\begin{array}{l}\text { Apanhar o produto acabado da } \\
\text { bancada de trabalho. (Proposta 1 } \\
\text { de automação) }\end{array}$ & 4 & $\begin{array}{l}\text { Encaixotar produto acabado dentro } \\
\text { da caixa de papelão }\end{array}$ \\
\hline 2 & $\begin{array}{l}\text { Destacar etiqueta do tipo 01 do } \\
\text { rolo. (Proposta 2 de automação) }\end{array}$ & 5 & $\begin{array}{l}\text { Destacar etiquetas dos tipos 02 } \\
\text { (etiqueta de tamanho); 03 (etiqueta } \\
\text { de marca) e 04 (etiqueta de preço) } \\
\text { dos rolos de etiquetas }\end{array}$ \\
\hline 3 & $\begin{array}{l}\text { Operador cola etiqueta do tipo 01 } \\
\text { no produto acabado. (Proposta 3 } \\
\text { de automação) }\end{array}$ & 6 & $\begin{array}{l}\text { Colar etiquetas dos tipos 02, 03 e } \\
\text { 04 na caixa }\end{array}$ \\
\hline
\end{tabular}

(*) Nesta operação será desenvolvida uma proposta de automação.

A Tab.2 apresenta uma relação de indicadores referentes ao produto A: 
TAS Journal, vol. 5, n. 2, p. 29-44

ISSN 2595-1521

MARCH 2021

giselecristinabessa@gmail.com

Tabela 2. Lista de indicadores do processo de etiquetagem do produto A (estado atual).

\begin{tabular}{|c|c|}
\hline Indicadores & Dados (estado atual) \\
\hline Tempo de ciclo total [s] & 126 \\
\hline $\begin{array}{c}\text { Capacidade do processo (considerando 82\% de } \\
\text { eficiência) [peças/dia] }\end{array}$ & 527 \\
\hline $\begin{array}{c}\text { Ocupação do processo [peças/dia] } \\
\text { Quantidade de operadores por turno } \\
\text { [operador/turno] }\end{array}$ & 500 \\
\hline Meta de produção [peças/turno] & $1 / 1^{\circ}$ turno \\
$1 / 2^{\circ}$ turno \\
$1 / 3^{\circ}$ turno \\
\hline $\begin{array}{c}1^{\circ} \text { turno }=206 \\
2^{\circ} \text { turno }=202 \\
3^{\circ} \text { turno }=119\end{array}$ \\
\hline Estimativa do custo com retrabalho [R \$/ano] & $15.000,00$ \\
\hline $\begin{array}{c}\text { Estimativa do custo com produtos devolvidos pelos } \\
\text { clientes [R } \$ / \text { ano] }\end{array}$ & $5.000,00$ \\
\hline
\end{tabular}

Os principais problemas encontrados no processo de etiquetagem do produto A, referentes às operações de apanhar produto acabado, retirar etiqueta do tipo 01 do rolo e colar etiqueta do tipo 01 no produto A são apresentados na Fig.2. 


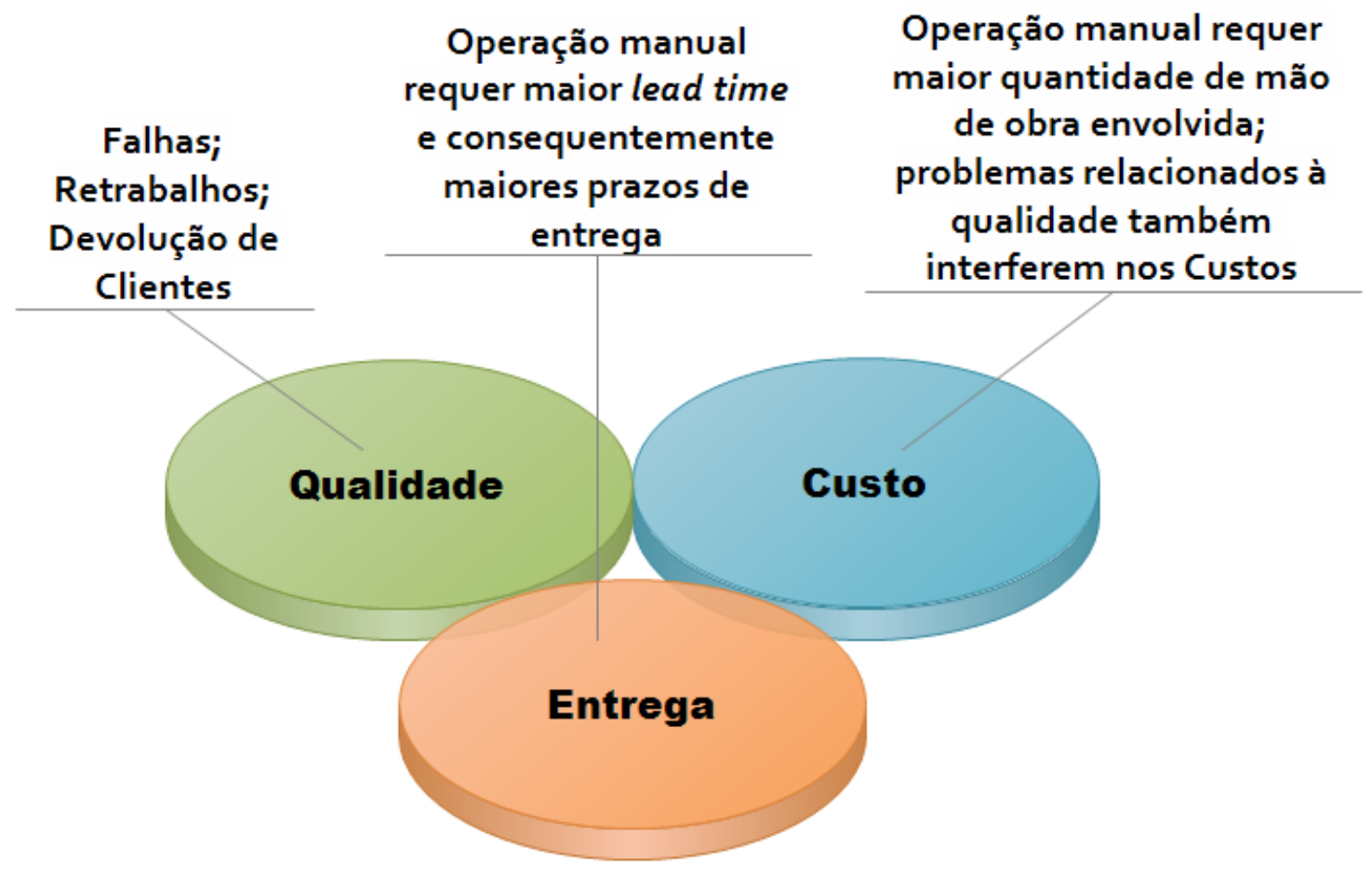

Figura 2. Problemas no processo de etiquetagem.

Requisitos gerais do Sistema. O projeto proposto tem como requisito funcional promover a automação de três operações do processo de etiquetagem do produto A; conferir as informações da etiqueta do tipo 01 conforme listado na ordem de produção $(\mathrm{OP})$ de serviço e gerenciar a planta automatizada para a colocação das etiquetas de forma autônoma (robotizada).

Neste projeto não será abordado a etiquetagem em produtos que sejam flexíveis, sendo objeto de projetos futuros a serem desenvolvidos.

$\mathrm{Na}$ Tab.3 os requisitos estruturais do sistema foram definidos de acordo com a caracterização do processo atual de etiquetagem do produto $\mathrm{A}$. 
TAS Journal, vol. 5, n. 2, p. 29-44

ISSN 2595-1521

MARCH 2021

giselecristinabessa@gmail.com

Tabela 3. Requisitos estruturais do sistema.

\begin{tabular}{|c|c|}
\hline Etapa 01 - Aplicação da etiqueta & Etapa 02 - Deslocamento embalagem \\
\hline $\begin{array}{l}\text { a) Espaço de trabalho tridimensional }\left(\Lambda^{* *}=6\right) \text {, } \\
\text { deslocamento nos eixos X, Y e Z. Mobilidade } \\
=3 \text {. }\end{array}$ & $\begin{array}{l}\text { a) Espaço de trabalho planar }(K=3) \text {, } \\
\text { deslocamento nos eixos X e Z. Mobilidade }=3 \text {. }\end{array}$ \\
\hline $\begin{array}{l}\text { b) Deslocamento em } \mathrm{X} \text { até } 800 \mathrm{~mm} \text { acionado } \\
\text { por motor de passo Nema } 23 \text { por cremalheira } \\
\text { sobre guias lineares }\end{array}$ & $\begin{array}{l}\text { b) Deslocamento em X até } 900 \mathrm{~mm} \text { acionado } \\
\text { por pistão pneumático }\end{array}$ \\
\hline $\begin{array}{l}\text { c) Deslocamento em Y até } 700 \mathrm{~mm} \text { acionado } \\
\text { por pistão pneumático por fuso sobre guias } \\
\text { lineares }\end{array}$ & $\begin{array}{l}\text { c) Deslocamento em Y até } 700 \mathrm{~mm} \text { por pistão } \\
\text { pneumático }\end{array}$ \\
\hline $\begin{array}{l}\text { d) Deslocamento em Z } 400 \mathrm{~mm} \text { acionado por } \\
\text { pistão pneumático }\end{array}$ & \\
\hline
\end{tabular}

**A rigor matemático, o espaço de trabalho $(K)$ constitui a base vetorial dos movimentos permitidos de um corpo rígido, assim, um corpo livre no espaço tridimensional $(K=6)$ apresenta seis possíveis movimentos independentes (Tx, Ty, Tz, Rx, Ry, Rz), enquanto um corpo livre no espaço planar apresenta três possíveis movimentos independentes (Tx, Ty, Rz).

Para este processo de automação industrial será utilizado um robô com dimensões de $1.600 \mathrm{~mm}$ de largura, $800 \mathrm{~mm}$ de comprimento e $400 \mathrm{~mm}$ de altura, com configuração de regulagem de altura, para diferentes alturas de embalagens até $400 \mathrm{~mm}$, sendo o mesmo acionado por motor elétrico com reversão de rotação.

O robô estará posicionado sobre duas esteiras conectadas em paralelo com sentidos opostos de movimentação, acionadas por motores elétricos com caixa de redução e controladas por inversores de frequência.

Para este tipo de proposta de automação não há necessidade de o robô ser leve nem compacto, devido às dimensões disponíveis no local. As esteiras devem estar posicionadas a $850 \mathrm{~mm}$ de altura, para a colocação das embalagens sobre a esteira, de maneira ergonômica. As embalagens terão as dimensões máximas de $700 \mathrm{~mm}$ x $500 \mathrm{~mm}$ x $170 \mathrm{~mm}$, com peso de $0,30 \mathrm{~kg}$ e as etiquetas vão variar as dimensões de $40 \mathrm{~mm}$ x $30 \mathrm{~mm}$ até $70 \mathrm{~mm}$ x $55 \mathrm{~mm}$, conforme solicitação do cliente.

O sistema será controlado por um controlador lógico programável (CLP) em que a máquina estará conectada a nuvem, que receberá as informações da OP de serviço a ser executada. As informações referentes ao tipo e dimensões das etiquetas serão conferidas com a leitura do código QRcode conforme cadastro presente na OP de serviço. A interação com o operador para seleção da OP será por intermédio de um tablet conectado a um sistema de produção online via WIFI em um servidor na nuvem. A operação do equipamento será feita por intermédio de interface homem máquina 
IHM. O CLP terá 3 entradas digitais para sensores fotoelétricos, 9 saídas digitais, das portas de comunicação serial para a IHM e o leitor de QRcode, conforme apresentado na Tab.4.

Tabela 4. Lista de funcionamento do sistema proposto.

\begin{tabular}{|c|l|c|l|}
\hline Quantidade & \multicolumn{1}{|c|}{ Descritivo } & Quantidade & \multicolumn{1}{|c|}{ Descritivo } \\
\hline 1 & $\begin{array}{l}\text { a) Sensor posicionamento do } \\
\text { produto A }\end{array}$ & 1 & $\begin{array}{l}\text { g) Pistão da câmara de geração de } \\
\text { vácuo da ventosa que segura a } \\
\text { etiqueta no translado }\end{array}$ \\
\hline 1 & $\begin{array}{l}\text { b) Sensor posicionamento da } \\
\text { etiqueta }\end{array}$ & 2 & $\begin{array}{l}\text { h) Motor CC para regulagem de } \\
\text { altura }\end{array}$ \\
\hline 1 & $\begin{array}{l}\text { c) Sensor do motor de passo } \\
\text { de controle da etiqueta }\end{array}$ & 2 & $\begin{array}{l}\text { i) Saídas de controle de } \\
\text { acionamento dos motores das } \\
\text { esteiras }\end{array}$ \\
\hline 1 & $\begin{array}{l}\text { d) Pistão de parada do produto } \\
\text { A na esteira }\end{array}$ & 2 & $\begin{array}{l}\text { j) Saídas PWM para controle do } \\
\text { posicionamento do motor de } \\
\text { passo do eixo X outro motor de } \\
\text { passo do desbobinador de } \\
\text { etiqueta }\end{array}$ \\
\hline 2 & $\begin{array}{l}\text { e) Pistões de deslocamento } \\
\text { entre esteiras }\end{array}$ & 2 & $\begin{array}{l}\text { k) Saídas analógicas de controle } \\
\text { de velocidade das esteiras }\end{array}$ \\
\hline 1 & $\begin{array}{l}\text { f) Pistão de posicionamento } \\
\text { da etiqueta }\end{array}$ & \multicolumn{2}{|l}{} \\
\hline &
\end{tabular}

Em todo o comando será usado tensão de $24 \mathrm{Vcc}$, que contará com estrutura de carenagem de isolamento para evitar aproximação de pessoas das partes móveis do equipamento. Haverá também 3 botoeiras de emergência ao redor do equipamento.

Engenharia conceitual da solução do problema. O produto A chegará na linha de produção de etiquetagem em um carrinho e será descarregado sobre a esteira de alimentação da máquina. Em seguida, o robô fará a colagem da etiqueta na posição configurada de acordo com o modelo cadastrado no sistema, conforme OP de serviço. A Tab.5 descreve os processos desde o recebimento das informações da OP até o encaminhamento do produto A para a etapa final. 
TAS Journal, vol. 5, n. 2, p. 29-44

ISSN 2595-1521

MARCH 2021

giselecristinabessa@gmail.com

Tabela 5. Processo de automação de etiquetagem industrial do produto A.

\begin{tabular}{|c|l|c|l|}
\hline Etapa & \multicolumn{1}{|c|}{ Descrição } & Etapa & \multicolumn{1}{|c|}{ Descrição } \\
\hline 1 & $\begin{array}{l}\text { Máquina recebe as informações da } \\
\text { OP }\end{array}$ & 6 & $\begin{array}{l}\text { Robô destaca a etiqueta do rolo de } \\
\text { etiquetas }\end{array}$ \\
\hline 2 & $\begin{array}{l}\text { Operador confirma a etiqueta } \\
\text { escolhida com leitor de código } \\
\text { QRcode }\end{array}$ & 7 & Robô cola a etiqueta no produto A \\
\hline 3 & $\begin{array}{l}\text { Operador insere bobina com as } \\
\text { etiquetas }\end{array}$ & 8 & $\begin{array}{l}\text { Robô desloca o produto A para a } \\
\text { esteira de saída }\end{array}$ \\
\hline 4 & $\begin{array}{l}\text { Operador retira o produto A do } \\
\text { carrinho e coloca sobre a esteira de } \\
\text { entrada }\end{array}$ & 9 & $\begin{array}{l}\text { Operador retira o produto A da } \\
\text { esteira e coloca o produto no } \\
\text { carrinho }\end{array}$ \\
\hline 5 & $\begin{array}{l}\text { Robô posiciona o produto A para } \\
\text { a colagem de etiqueta }\end{array}$ & \multicolumn{2}{l}{} \\
\hline
\end{tabular}

Critérios de projeto. O equipamento deverá posicionar as etiquetas corretas de acordo com cada tipo de produto (neste caso conforme o produto A anteriormente determinado), na posição adequada conforme especificação e capacidade de etiquetar 1.000 peças/h.

No entanto, para o estudo em questão, a máquina poderá trabalhar para etiquetar apenas a quantidade desejada, que neste caso é de 500 peças/dia.

Caracterização detalhada do projeto. Conforme ilustrado na Fig.5, o sensor S1 verifica a presença de etiqueta no destacador de etiquetas; o sensor S2 verifica se o produto A está posicionado, caso não, o pistão pneumático "A" recua para liberação do próximo produto, sendo que a esteira de entrada e saída permanecem sempre ligadas. Quando o sensor S2 identifica o produto A, aciona o pistão pneumático "A", aciona o pistão pneumático "B" até a etiqueta, recua o pistão pneumático " $C$ " da ventosa, recua o pistão pneumático " $\mathrm{B}$ " com a etiqueta, desloca $o$ conjunto pelo motor de passo até na posição " $\mathrm{X}$ " determinada e aciona o pistão pneumático " $\mathrm{B}$ " $\mathrm{e}$ o pistão pneumático "C" para colar a etiqueta.

Feito isso, recua o pistão pneumático "B" e volta o conjunto a posição inicial. Posteriormente, o pistão pneumático " $\mathrm{D}$ " aciona para encostar na lateral do produto A e recua o pistão pneumático "E" para deslocar o produto A para a esteira de saída, em seguida recua o pistão pneumático "D" e aciona o pistão pneumático "E" para a posição inicial. O sensor S1 verifica que não tem etiqueta e aciona o motor de passo para posicionar a etiqueta e o sensor S3 controla o motor de passo que posiciona a etiqueta. O diagrama de E-P-S é apresentado na Fig.5. 
TAS Journal, vol. 5, n. 2, p. 29-44

ISSN 2595-1521

MARCH 2021

giselecristinabessa@gmail.com

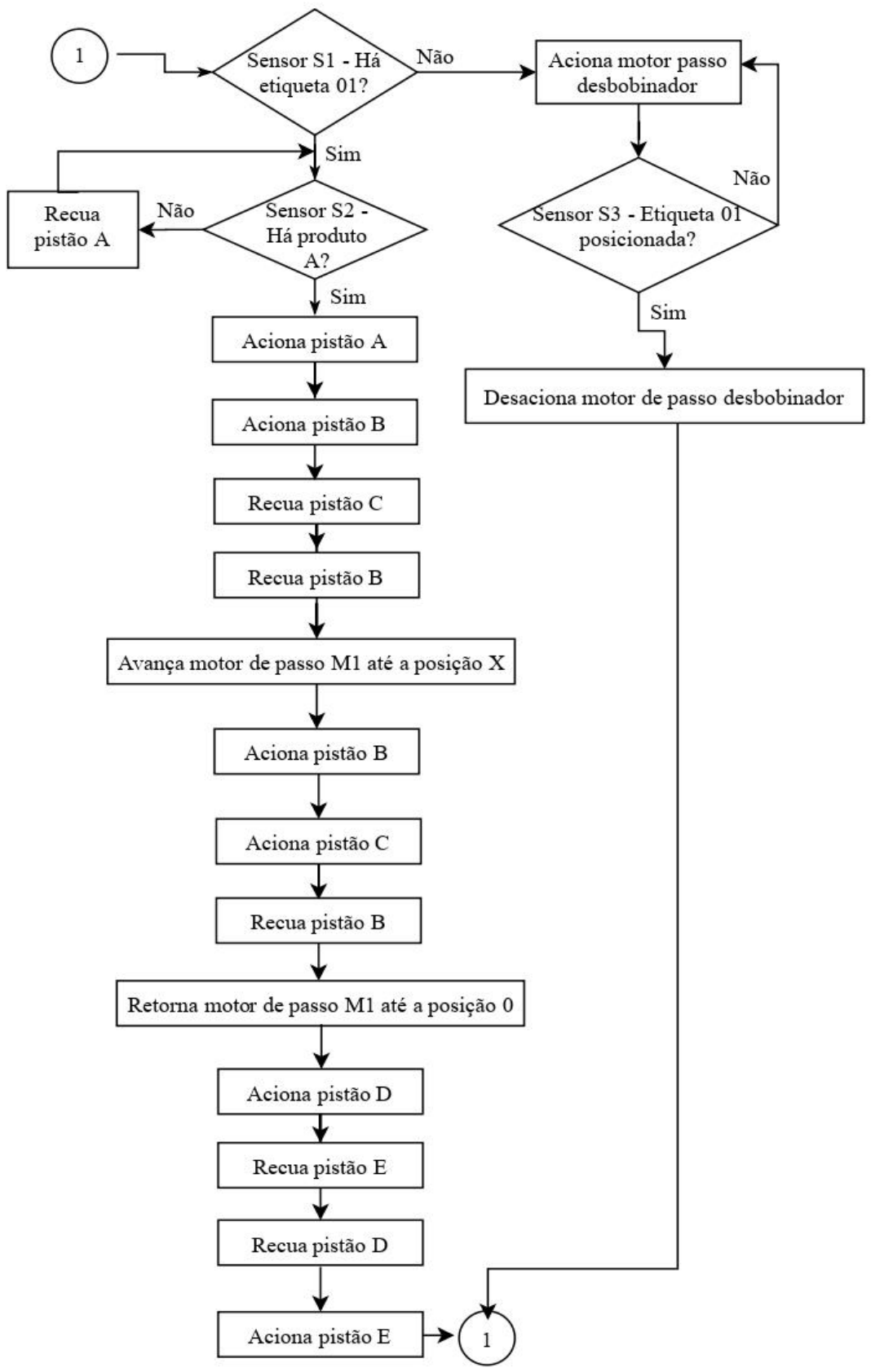

Figura 5. Diagrama de E-P-S do projeto.

Desenvolvimento técnico de sistemas e subsistemas. A equação de movimento para este processo de automação será: A+, B+, C-, B-, M1+, B+, C+, B-, M-, D+, E-, D-, E+, A-. 
De acordo com a Fig. 6, o cilindro A terá a dimensão de $25 \mathrm{~mm}$ de diâmetro com haste de 300mm, o cilindro B terá a dimensão de $25 \mathrm{~mm}$ de diâmetro com haste de $400 \mathrm{~mm}$, o cilindro C terá a dimensão de $16 \mathrm{~mm}$ de diâmetro com haste de $100 \mathrm{~mm}$, o cilindro D terá a dimensão de $25 \mathrm{~mm}$ de diâmetro com haste de $700 \mathrm{~mm}$ e o cilindro E terá a dimensão de $40 \mathrm{~mm}$ de diâmetro com haste de $900 \mathrm{~mm}$. Os pistões são todos de dupla ação e serão controlados por válvulas $5 / 2$ vias retorno por mola com solenoide de 24 Vcc. A ilustração da esteira é exemplificada na Fig.6.

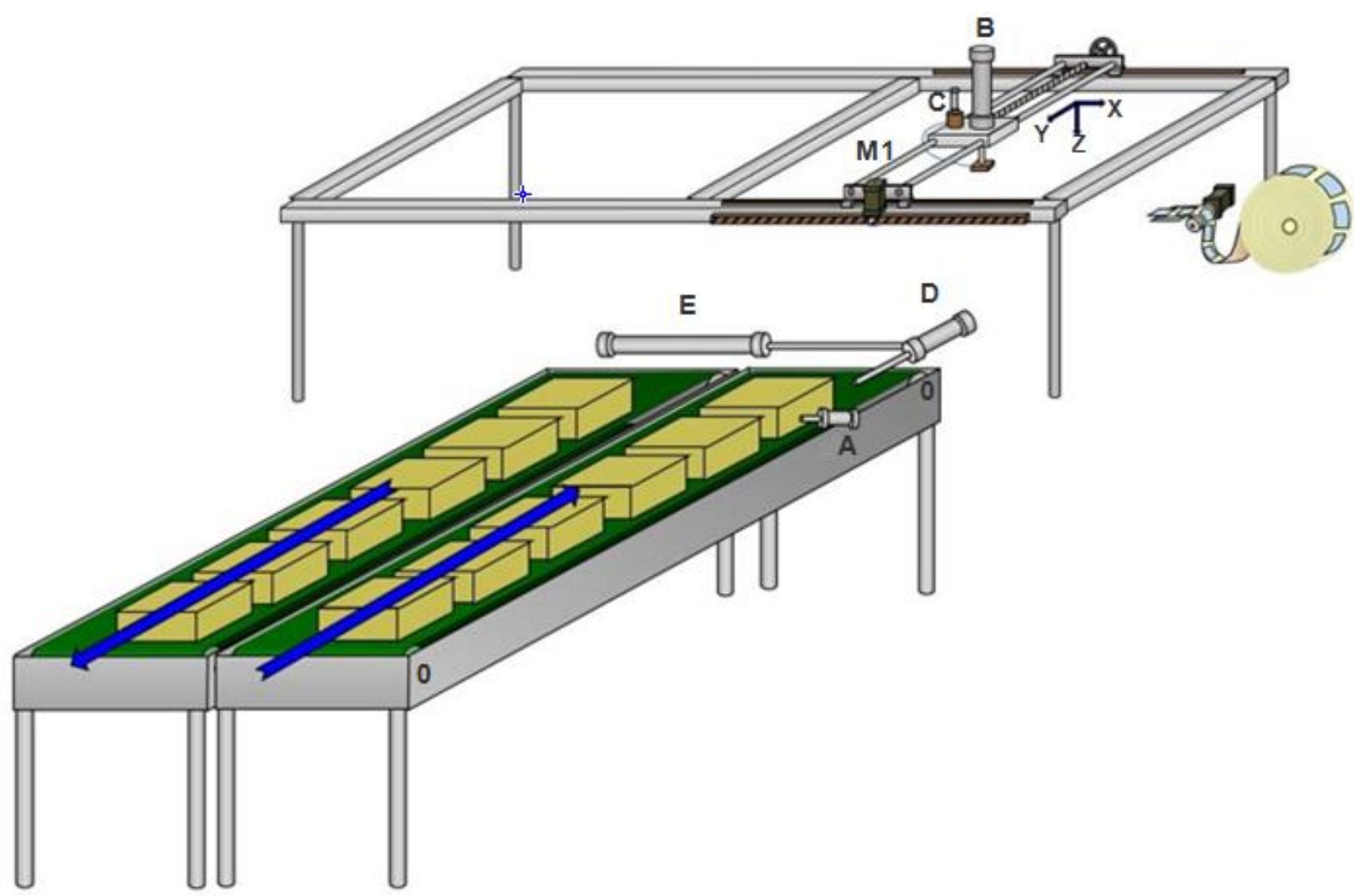

Figura 6. Ilustração esquemática da planta industrial proposta.

Conforme Fig.7, a esteira terá $800 \mathrm{~mm}$ de largura x $5.000 \mathrm{~mm}$ de comprimento, acionada por moto redutor de 1:80 com motor da marca WEG de 1,5 CV - 4 polos - $380 \mathrm{~V}$, trifásico, controlados por inversor da marca WEG. A Fig.7 apresenta os detalhes do mecanismo de retirada e colagem de etiquetas proposto. 


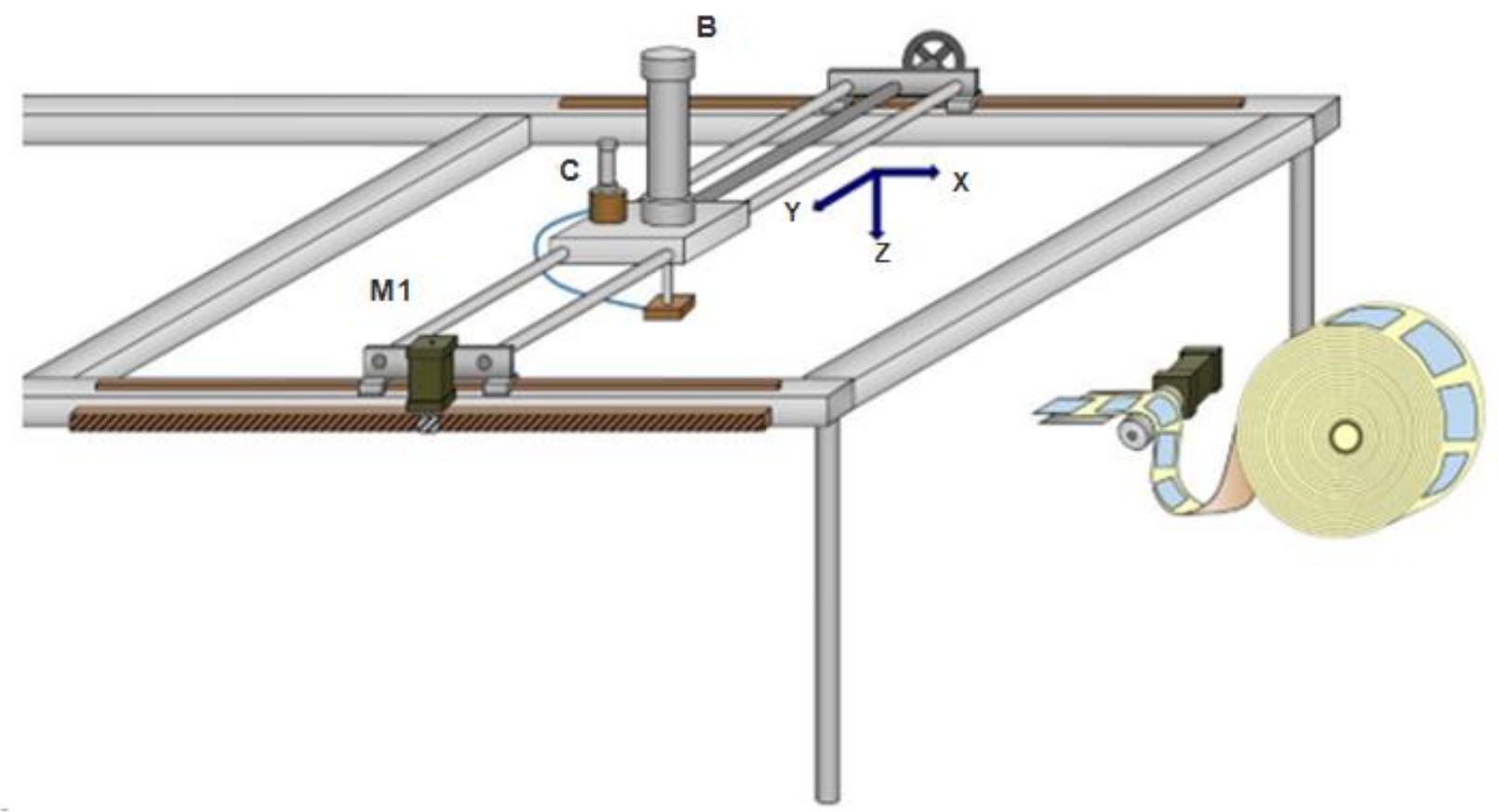

Figura 7. Mecanismo de etiquetagem automático.

O CLP será dedicado com IHM de 7" touchscreen de tela capacitiva da marca Nextion e conectará com o sistema de Produção Online da LH Engenharia. Os sensores fotoelétricos de reflexão difusa serão da marca Banner.

Os motores de passo serão Nema 23 com torque de $2,8 \mathrm{~N} / \mathrm{m}$ controlados por drive fornecidos pela Kalatec. Motor CC Bosch 24Vcc 10 N/m - 56 rpm.

Resultados. A Fig.8 ilustra o processo de etiquetagem após a automação das operações de apanhar produto acabado, destacar etiqueta do tipo 01 do rolo e colar etiqueta do tipo 01 no produto A (após implementação do projeto). 


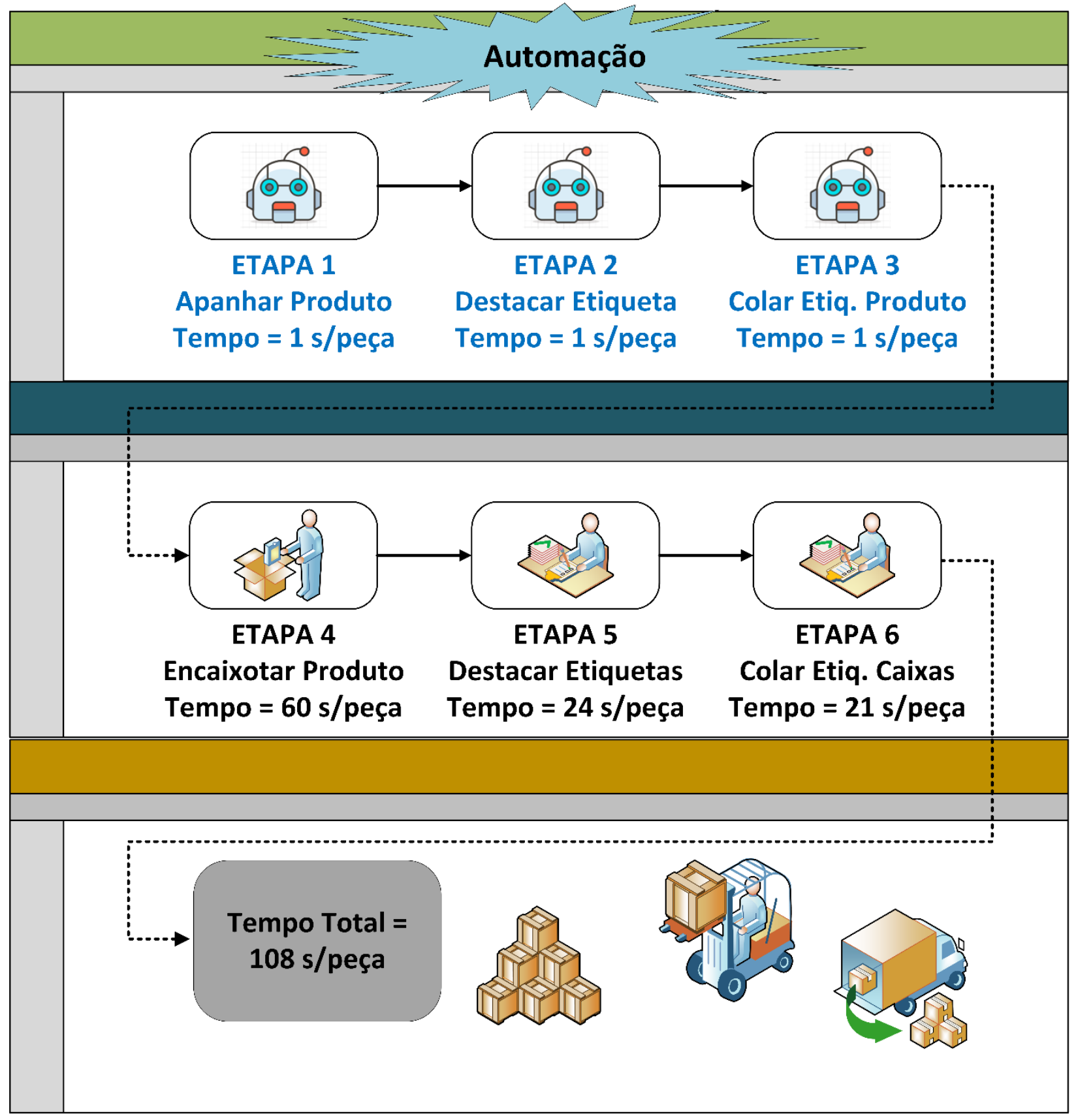

Figura 8. Processo de etiquetagem de embalagem do produto A (estado futuro).

Pode-se observar, comparando os tempos apresentados na Fig. 8 com os da Fig.1, que o processo proposto trará uma redução de tempo de aproximadamente $14,3 \%$.

A Tab.6 traz uma lista de indicadores referentes ao produto A. 
TAS Journal, vol. 5, n. 2, p. 29-44

ISSN 2595-1521

MARCH 2021

giselecristinabessa@gmail.com

Tabela 6. Lista de indicadores do processo de etiquetagem de embalagem do produto A (estado atual X estado futuro, previsto após implantação do projeto).

\begin{tabular}{|c|c|c|}
\hline Indicadores & Dados (estado atual) & Dados (estado futuro) \\
\hline Tempo de ciclo total [s] & 126 & 108 \\
\hline Capacidade [peças/dia] & \begin{tabular}{l}
\multicolumn{1}{c}{527} \\
Obs.: Considerando $82 \%$ \\
de eficiência
\end{tabular} & \begin{tabular}{l}
\multicolumn{4}{c}{637} \\
Obs.: Considerando $85 \%$ \\
de eficiência devido \\
automação
\end{tabular} \\
\hline $\begin{array}{l}\text { Ocupação do processo } \\
\text { [peças/dia] }\end{array}$ & 500 & $500(* * *)$ \\
\hline $\begin{array}{l}\text { Quantidade de operadores } \\
\text { por turno [operador/turno] }\end{array}$ & $\begin{array}{l}1^{\circ} \text { turno }=1 \\
2^{\circ} \text { turno }=1 \\
3^{\circ} \text { turno }=1\end{array}$ & $\begin{array}{l}\qquad 1^{\circ} \text { turno }=1 \\
2^{\circ} \text { turno }=1 \\
3^{\circ} \text { turno }=25,5 \% \text { do tempo } \\
\text { de } 1 \text { operador }\end{array}$ \\
\hline $\begin{array}{l}\text { Meta de produção } \\
\text { [peças/turno] }\end{array}$ & $\begin{array}{c}1^{\circ} \text { turno }=206 \\
2^{\circ} \text { turno }=202 \\
3^{\circ} \text { turno }=119 \\
\text { Total }=527\end{array}$ & $\begin{array}{c}1^{\circ} \text { turno }=249 \\
2^{\circ} \text { turno }=243 \\
3^{\circ} \text { turno }=35(* * * *) \\
\text { Total }=527\end{array}$ \\
\hline $\begin{array}{l}\text { Estimativa do custo com } \\
\text { retrabalho }[\mathrm{R} \$ / \mathrm{ano}]\end{array}$ & $15.000,00$ & $1.500,00$ \\
\hline $\begin{array}{c}\text { Estimativa do custo com } \\
\text { devolução de cliente } \\
\text { [R \$/ano] }\end{array}$ & $5.000,00$ & 500,00 \\
\hline
\end{tabular}

(***) Com a melhoria no processo, a capacidade do estado futuro aumenta, porém a ocupação do processo (demanda gerada pelas vendas) permanecerá em 500 peças por dia. Entretanto nessa nova condição o processo já está adequado para atender a uma expansão de produção sinalizada pela empresa.

(****) Do total da meta de 527 peças por dia restaram somente 35 para serem produzidas no $3^{\circ}$ turno, já que na situação futura, o impacto da automação acelera a produção fazendo com que o $1^{\circ}$ e $2^{\circ}$ turno produzam mais peças. Consequentemente sobra menos peças a serem produzidas pelo

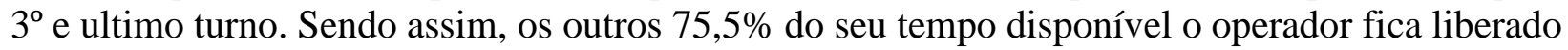
para realizar trabalho em outros processos/máquinas. 
Comparando os resultados do estado atual com a prevista com a implementação do projeto, o estado futuro, através da proposta de automação para determinadas operações do processo de etiquetagem, pode-se observar que o tempo de ciclo teve uma redução de $14,3 \%$.

Como a demanda não mudará neste momento, 75,5\% do tempo disponível do operador do $3^{\circ}$ turno poderá ser direcionado para outra linha de produção. Por consequência, a automação também trará reduções nos indicadores de retrabalho e devolução de produtos pelos clientes.

Impacto Ambiental. $O$ projeto proposto não gera nenhum tipo de impacto ambiental, não produzindo lixo, nem efluentes e nenhum tipo de contaminação. Além disso, traz o benefício de evitar o desperdício de etiquetas na indústria têxtil, pois pela adesão à esta proposta de automação, o desperdício de etiquetas é zerado. Portanto, o presente projeto contribui ambientalmente com a redução de lixo causada pelo processo de etiquetagem.

Conclusão. Foi apresentada a proposta de automação do processo de etiquetagem de produtos, e a otimização industrial em termos de qualidade do produto e de tempo de ciclo. Estes parâmetros foram mensurados quantitativamente, baseado em estimativas do processo, obtendo redução de não conformidades e uma redução de tempo de ciclo do processo de 14,3\%, após a implementação do projeto proposto, impactando na redução de 75,5\% do tempo de um dos operadores.

Muito embora a proposta apresentada seja limitada à rotulagem de produtos rígidos, os benefícios previstos já foram relevantes. Este estudo poderá ser ampliado abrangendo o processo de etiquetagem de produtos têxteis que não possuam firmeza/sustentação, ou seja, produtos flexíveis dentro da sua embalagem, onde existe uma grande demanda no seguimento da indústria têxtil e confecção.

O estudo apresentou uma alternativa de projeto de automação para o setor têxtil e confecção, motivando à modernização da indústria, mostrando que mesmo, a partir de ações simples, como a introdução de sistemas automatizados, aproximam a evolução da indústria para o grande desafio a ser alcançado, a indústria 4.0, que apesar de distante ainda neste setor, será a base para a sua competitividade no mercado global.

Agradecimentos. Os autores agradecem à Coordenação de Aperfeiçoamento de Pessoal de Nível Superior (CAPES) pelo auxílio no atual trabalho.

Conflitos de interesse. Os autores declaram que não há conflito de interesse. 


\section{Referências}

(1) Nayak R, Padhye R. Introduction automation in garment manufacturing. Automation in garment manufacturing. 2018:1-27.

(2) Ruikar DR, Santosh KC, Hegadi RS. Automated fractured bone segmentation and labeling from CT images. J. Med. Syst. 2019;43:2-13.

(3) Simonis K, Gloy YS, Gries T. Industrie 4.0 - Automation in weft knitting technology. IOP Conf. Ser. Mater. Sci. Eng. 2016;141:0-10.

(4) Papoutsidakis M, Piromalis D, Priniotakis G. Advanced automation in textile industry production lines. Int. J. Eng. Appl. Sci. Technol. 2019;4:504-507.

(5) Küsters D, Praß N, Gloy YS. Textile Learning Factory 4.0 - Preparing Germany's textile industry for the digital future. Procedia Manuf. 2017;9:214-221.

[6) Castrucci PL, Moraes CC. Engenharia de automação industrial. 2007.

(7) Parschau C, Hauge J. Is automation stealing manufacturing jobs? Evidence from South Africa's apparel industry. Geoforum. 2020;115:120-131.

(8) Madakam S, Holmukhe RM, Jaiswal DK. The future digital work force: robotic process automation (RPA). J. Inf. Syst. Technol. Manag. 2019;16:1-17.

(9) Jiménez-Schlegl P, Cubrić G. Robots in the Textile and Fashion Industries: Facts and Prospectives; [Atualizado em janeiro de 2018; citado em março de 2021]. Disponível em https://digital.csic.es/handle/10261/180026.

(10) Michalos G et al. Seamless human robot collaborative assembly - An automotive case study. Mechatronics. 2018:1-18.

(11) Suh M. Automated cutting and sewing for industry 4.0 at ITMA 2019. J. Text. Apparel. Technol. Manag. 2019;11:1-13.

(12) Puranikmath AV, Babu KM. Application of internet of things in smart textile and apparel manufacturing. World J. of Text. Eng. and Technol. 2020;6:39-51.

(13) Freitas JAS, Guimarães, BKB. Cadeia global de valor na indústria têxtil: uma aproximação. 2019.

(14) Stival SW et al. Estudo de tempos e movimentos: análise do processo produtivo na confecção de camisetas. 2018. 